\title{
Selective Transgenic Expression of Mutant Ubiquitin in Purkinje Cell Stripes in the Cerebellum
}

\author{
Bert M. Verheijen ${ }^{1,2}$ • Romina J. G. Gentier ${ }^{1}$ - Denise J. H. P. Hermes ${ }^{1}$ • \\ Fred W. van Leeuwen ${ }^{1}$ • David A. Hopkins ${ }^{1,3}$
}

Published online: 13 December 2016

(C) The Author(s) 2016. This article is published with open access at Springerlink.com

\begin{abstract}
The ubiquitin-proteasome system (UPS) is one of the major mechanisms for protein breakdown in cells, targeting proteins for degradation by enzymatically conjugating them to ubiquitin molecules. Intracellular accumulation of ubiquitin- $\mathrm{B}^{+1}\left(\mathrm{UBB}^{+1}\right)$, a frameshift mutant of ubiquitin-B, is indicative of a dysfunctional UPS and has been implicated in several disorders, including neurodegenerative disease. $\mathrm{UBB}^{+1}$-expressing transgenic mice display widespread labeling for $\mathrm{UBB}^{+1}$ in brain and exhibit behavioral deficits. Here, we show that $\mathrm{UBB}^{+1}$ is specifically expressed in a subset of parasagittal stripes of Purkinje cells in the cerebellar cortex of a $\mathrm{UBB}^{+1}$-expressing mouse model. This expression pattern is reminiscent of that of the constitutively expressed Purkinje cell antigen HSP25, a small heat shock protein with neuroprotective properties.
\end{abstract}

Keywords Ubiquitin-proteasome system $\cdot$ Ubiquitin- $\mathrm{B}^{+1}$. Purkinje cell stripes $\cdot$ Zebrin II $\cdot$ Heat shock protein 25 . Cerebellum

Bert M. Verheijen

1.m.verheijen-3@umcutrecht.nl

1 Department of Neuroscience, Faculty of Health, Medicine and Life Sciences, Maastricht University, Maastricht, The Netherlands

2 Present address: Lab of Experimental Neurology, Brain Center Rudolf Magnus, University Medical Center Utrecht, Utrecht, The Netherlands

3 Department of Medical Neuroscience, Dalhousie University, Halifax, Nova Scotia, Canada

\section{Introduction}

Efficient protein quality control is essential for the maintenance of cellular homeostasis to prevent accumulation of damaged and toxic proteins that would be detrimental to cells and their function. The ubiquitin-proteasome system (UPS) is one of the major mechanisms for targeted protein breakdown in cells, tagging proteins for degradation by enzymatically conjugating them to ubiquitin molecules [1, 2]. Impaired protein quality control and degradation are often associated with aging and disease [3, 4].

Ubiquitin- $\mathrm{B}^{+1}\left(\mathrm{UBB}^{+1}\right)$ is a frameshift mutant of ubiquitin$\mathrm{B}$ (UBB) that has been found to accumulate in a variety of disorders, including neurodegenerative diseases $[5,6]$. $\mathrm{UBB}^{+1}$ is thought to arise through "molecular misreading," a process that introduces mutations not present in genomic DNA into repeating motifs (e.g., GAGAG motifs) of mRNA resulting in mutant proteins $[5,7]$. $\mathrm{UBB}^{+1}$ lacks a C-terminal glycine residue and therefore cannot ubiquitinate other proteins, but can still be ubiquitinated itself. Low levels of $\mathrm{UBB}^{+1}$ are efficiently degraded by the proteasome via the ubiquitin-fusion degradation (UFD) pathway [8]. At high concentrations, however, $\mathrm{UBB}^{+1}$ is a potent inhibitor of the UPS [9, 10]. Interestingly, studies in yeast have indicated that $\mathrm{UBB}^{+1}$ is an inhibitor of deubiquitinating enzymes (DUBs) [11]. In addition, $\mathrm{UBB}^{+1}$ causes neuritic beading of mitochondria in association with neuronal degeneration [12]. This suggested an effect of $\mathrm{UBB}^{+1}$ on mitochondrial function. It was recently reported that accumulation of basic amino acids at mitochondria dictates the cytotoxicity of $\mathrm{UBB}^{+1}[13]$.

To study the effects of $\mathrm{UBB}^{+1}$ accumulation in vivo, $\mathrm{UBB}^{+1}$-expressing mouse models have been generated. Transgenic mice overexpressing human $\mathrm{UBB}^{+1}$ in brain show increased levels of ubiquitinated proteins in the forebrain and display behavioral deficits (e.g., impaired 
contextual memory) that are compatible with neurodegenerative disease [14].

Crossbreeding $\mathrm{UBB}^{+1}$ mice to relevant disease models has shown disease-modifying effects $[15,16]$. A comprehensive phenotypic screening of $\mathrm{UBB}^{+1}$-expressing mice revealed a respiratory phenotype [17]. Concordantly, expression of $\mathrm{UBB}^{+1}$ was found in brainstem nuclei involved in respiratory control. $\mathrm{UBB}^{+1}$ immunoreactivity in Alzheimer's disease (AD) patients was seen in similar areas in the brainstem, suggesting a link between neuropathology in these brainstem areas and the respiratory and swallowing dysfunctions that are often seen in AD patients [17].

In the present study, we show that $\mathrm{UBB}^{+1}$ is specifically expressed in a subset of parasagittal stripes of Purkinje cells (PCs) in the cerebellar cortex of a $\mathrm{UBB}^{+1}$-expressing mouse model. This expression pattern is similar to that of the constitutively expressed PC antigen HSP25.

\section{Materials and Methods}

\section{Animals}

$\mathrm{UBB}^{+1}$-expressing transgenic mice (line 3413, JAX C57BL/6-Tg(Camk2a-UBB)3413-1Fwvl/J) were described previously [14]. Male mice $(n=14$; eight 3month-old mice, two 7-month-old mice, and four 15month-old mice) were kept under standard animal housing conditions: a 12/12 h light-dark cycle with food and water ad libitum in specific pathogen-free conditions. Non-transgenic littermates were used as controls. All animal experiments were performed according to national animal welfare law and under guidance of the animal welfare committees of the Royal Netherlands Academy of Arts and Sciences (KNAW) and of Maastricht University.

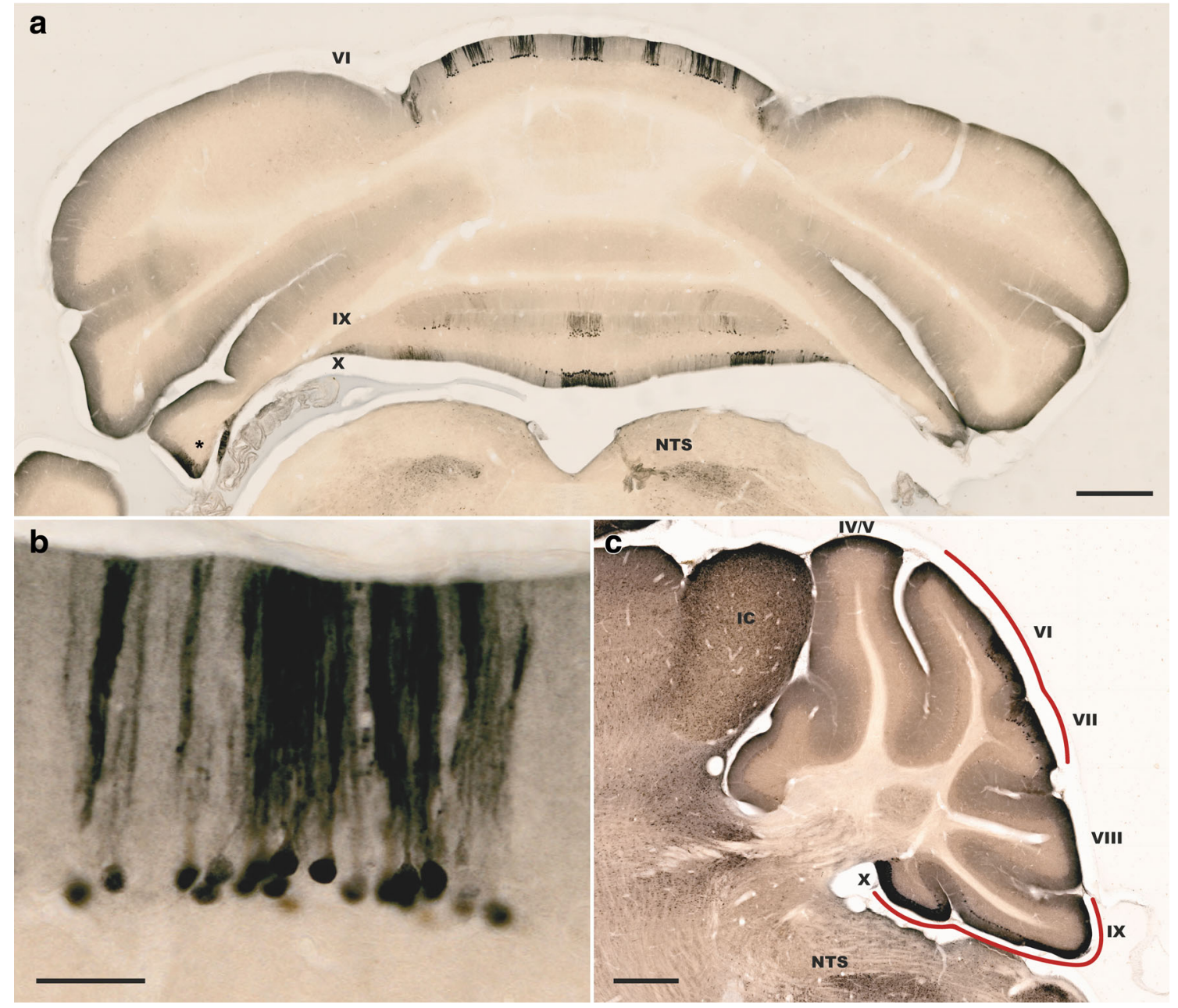

Fig. 1 Expression pattern of mutant ubiquitin $\left(\mathrm{UBB}^{+1}\right)$ in the mouse cerebellum. Distribution of $\mathrm{UBB}^{+1}$ in the cerebellum of a $\mathrm{UBB}^{+1}$ expressing transgenic mouse line. A coronal section reveals restricted expression of $\mathrm{UBB}^{+1}$ in parasagittal stripes of Purkinje cells $(P C s)$ in the vermis of the cerebellar cortex (a and $\mathbf{b})$. A sagittal overview shows expression of $\mathrm{UBB}^{+1}$ in lobules VI, VII, IX, and X (c). IC inferior colliculus, NTS nucleus of the solitary tract. Asterisk denotes additional $\mathrm{UBB}^{+1}$ expression in the cerebellar hemisphere. Scale bars a and $\mathbf{c}$ $500 \mu \mathrm{m}, \mathbf{b} 50 \mu \mathrm{m}$ 


\section{Tissue Processing and Immunohistochemistry}

Adult male mice were deeply anesthetized using sodium pentobarbital and were transcardially perfused with $0.9 \%$ $\mathrm{NaCl}$, followed by $4 \%$ paraformaldehyde in phosphatebuffered saline (PBS) (pH 7.4). After removal, the brains were fixed overnight in $0.1 \mathrm{M}$ phosphate buffer containing $4 \%$ paraformaldehyde ( $\mathrm{pH}$ 7.4). The brains were subsequently stored in $1 \%$ sodium azide $\left(\mathrm{NaN}_{3}\right)$ in PBS at $4{ }^{\circ} \mathrm{C}$ until further processing. All brains were embedded in gelatin and sectioned on a Vibratome (Leica VT 1200S, Wetzlar, Germany) into $50 \mu \mathrm{m}$ thick coronal or sagittal sections.

For immunohistochemistry, sections were incubated with primary antibodies at $4{ }^{\circ} \mathrm{C}$ overnight. Primary antibodies included the following: polyclonal rabbit antimouse $\mathrm{UBB}^{+1}$ (Ubi3, 1:1000, Dr. F.W. van Leeuwen, bleed date 16/09/97), monoclonal mouse anti-zebrin II/ aldolase C (1:100, Dr. R. Hawkes, Calgary), monoclonal mouse anti-calbindin-D28k (1:25,000, Swant), polyclonal rabbit anti-HSP25 (1:1000, Enzo Life Sciences), and monoclonal mouse anti-HSP25 (pHSP27 (B3), 1:400, Santa Cruz Biotechnology). Antibodies were diluted in Tris-buffered saline (TBS) containing $0.5 \%$ Triton $\mathrm{X}-100(\mathrm{pH} 7.6)$. After incubation with primary antibodies, sections were rinsed in TBS and incubated with biotinylated donkey anti-rabbit or anti-mouse antibodies (1:400) (Jackson Laboratories) followed by avidin-biotin-peroxidase (ABC) kit (Vector) at RT for $1 \mathrm{~h}$. The staining was visualized with 3,3'diaminobenzidine (DAB) tetrahydrochloride intensified by $0.2 \%$ nickel ammonium sulfate $(\mathrm{pH}$ 7.6). The sections were mounted on gelatin-coated glass slides, airdried, dehydrated, and coverslipped using Pertex (Histolab). For immunofluorescence experiments, secondary antibodies with a fluorescent tag (donkey antimouse/rabbit Alexa 488/594) were used. Images were made using an Olympus BX51 microscope connected to a digital camera or a whole-slide scanning system (.slide, Olympus).
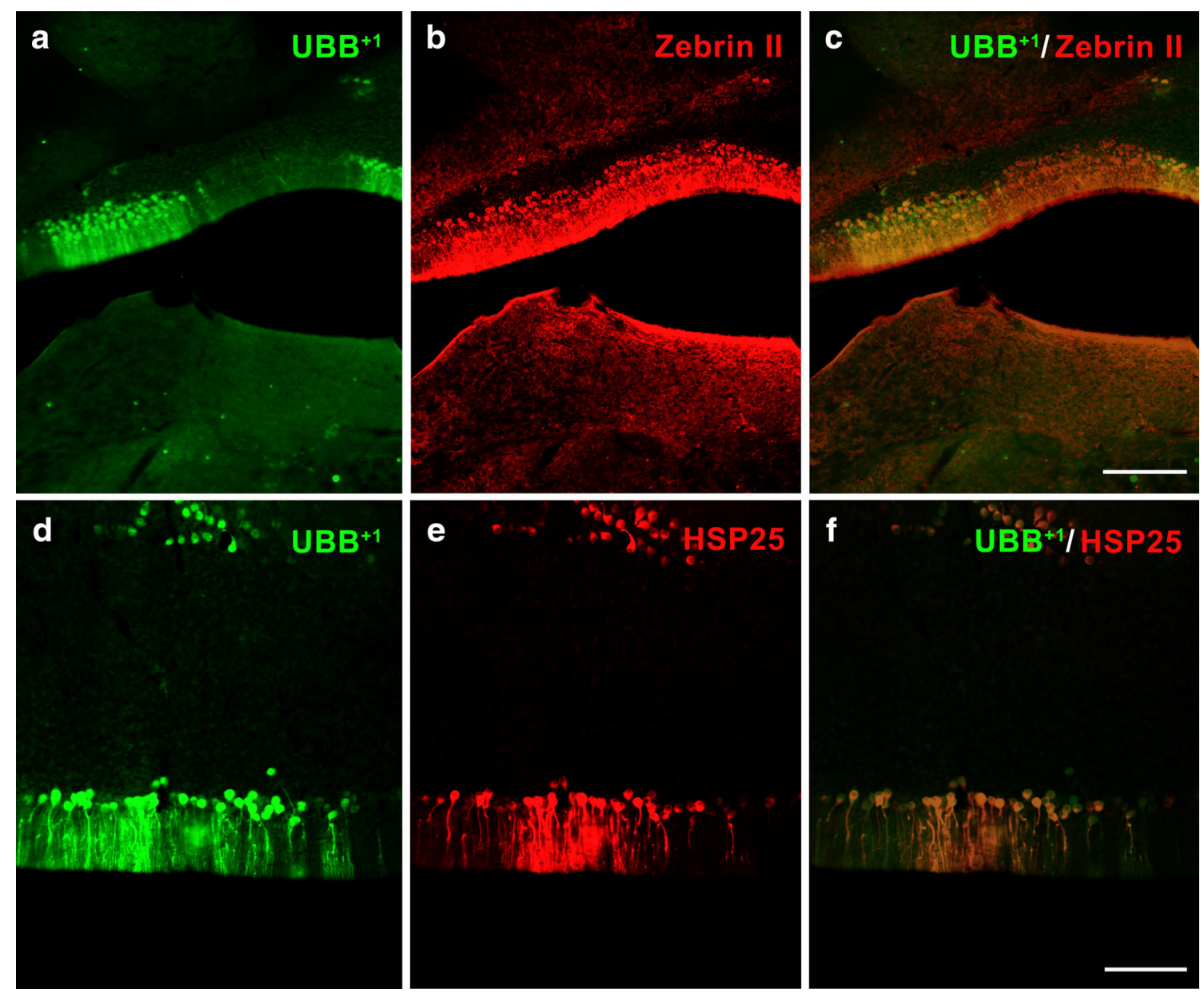

Fig. 2 Co-expression of mutant ubiquitin $\left(\mathrm{UBB}^{+1}\right)$ and HSP25 in Purkinje cell $(P C)$ stripes. $\mathrm{UBB}^{+1}$ is expressed in a subset of zebrin IIpositive $\mathrm{PC}$ stripes in the cerebellum of a $\mathrm{UBB}^{+1}$-expressing mouse line

(a-c). Co-immunofluorescence $(\mathbf{d}-\mathbf{f})$ shows co-expression of $\mathrm{UBB}^{+1}$ and HSP25. All sections are in the coronal plane (lobules IX-X). Scale bars a-c $200 \mu \mathrm{m}, \mathbf{d}-\mathbf{f} 100 \mu \mathrm{m}$ 


\section{Results and Discussion}

Transgenic mice expressing $\mathrm{UBB}^{+1}$ show a widespread distribution of $\mathrm{UBB}^{+1}$-positive neurons in the forebrain (e.g., cerebral cortex, striatum, hippocampal formation, and thalamus) as well as in the brainstem $[17,18]$. Here, we demonstrate that $\mathrm{UBB}^{+1}$ is also expressed in the cerebellum of a $\mathrm{UBB}^{+1}$-expressing mouse model. PC expression of the transgene is expected based on the use of the Camk2a gene promoter, a gene of well-known functional significance in these cells. Immunohistochemistry reveals that $\mathrm{UBB}^{+1}$-positive cerebellar PCs are always located within parasagittal stripes in cerebellar lobules VI, VII, IX, and X as well as in the flocculus and paraflocculus (Fig. 1). This pattern shows a striking resemblance to a previously identified marker for PC stripes, the small heat shock protein HSP25 (HSP27, HSPB1) [19]. The cerebellum is highly compartmentalized into bilaterally symmetric anatomical and functional clusters, which can be visualized through the expression of certain molecular markers [20, 21]. HSP25 is constitutively expressed in the central nervous system of rodents, notably in the cerebellum, brainstem, hypothalamus, and spinal cord [19, 22, 23]. HSP25 is known to act as a molecular chaperone and has been specifically associated with the functioning of the UPS. For example, HSP25 has been proposed to confer resistance to proteasome inhibition in astrocytes [24]. HSP25 also possesses neuroprotective properties; HSP25-positive PCs appear to be more resistant to cell death than HSP25-negative PCs, and HSP25 is highly stress-inducible throughout the nervous system $[25,26]$. Furthermore, differences in the expression of HSP25 have been reported in mutant mice and under the influence of genes controlling development [27, 28]. Further examination revealed that $\mathrm{UBB}^{+1}$-immunoreactive Purkinje neurons coexpress HSP25 (Fig. 2). $\mathrm{UBB}^{+1}$ is absent in all brain regions of control mice [29].

$\mathrm{UBB}^{+1}$ was also detected in cerebellar PC stripes in another $\mathrm{UBB}^{+1}$-expressing transgenic mouse line [30] (line 6663, unpublished observations). $\mathrm{UBB}^{+1}$-expressing transgenic mice do not display behavioral deficits in motor coordination tasks $[17,29]$ and no (focal) loss of PCs was observed (calbindinD28K immunostaining). Other changes in PC layer cytoarchitecture (e.g., dendrite complexity, synaptic connectivity, and structural plasticity) were not evaluated. Extensive molecular profiling of different PC clusters may provide new insights into important aspects of the fundamental anatomical organization of the cerebellum. HSP25-immunoreactive PCs are known to specifically express other markers, represent clusters that also include other cell types, and are associated with somatostatin 28-immunoreactive mossy fiber pathways $[31,32]$. These insights might also reveal several aspects of development and differential vulnerability of PC clusters and neural circuits in the cerebellum [33].
The 3413 transgenic line may be of great interest in the future for dissecting functional contributions of the cerebellum, PCs, and possibly even sagittal zones and stripes, in neurodegenerative diseases such as AD. Diffuse senile plaques occur commonly in the cerebellum of $\mathrm{AD}$ patients and certain patients present with cerebellar ataxias [34-37]. Some studies propose that PCs are key players in these ADassociated cerebellar defects $[38,39]$. Currently, there is no evidence of $\mathrm{PC}$ loss or axonal degeneration in these transgenic mice, but this should be examined in more detail in the future.

Acknowledgements The authors would like to thank Dr. Richard Hawkes (University of Calgary, Calgary, AB, Canada) for his generous gift of anti-zebrin II antibody and Dr. Carol Armstrong (Mount Royal University, Calgary, AB, Canada) for advice. FWvL received funding from the Internationale Stiching Alzheimer Onderzoek (ISAO, grant \# 06502 and 09514), Hersenstichting Nederland (2008.17 and 15F07.48), IPF 2008, and Van Leersum Foundation KNAW 2011. DAH was supported by an ISAO visiting professorship.

\section{Compliance with Ethical Standards}

Conflicts of Interest The authors declare that they have no conflict of interest.

Open Access This article is distributed under the terms of the Creative Commons Attribution 4.0 International License (http:// creativecommons.org/licenses/by/4.0/), which permits unrestricted use, distribution, and reproduction in any medium, provided you give appropriate credit to the original author(s) and the source, provide a link to the Creative Commons license, and indicate if changes were made.

\section{References}

1. Goldberg AL. Protein degradation and protection against misfolded or damaged proteins. Nature. 2003;426(6968):895-9.

2. Ciechanover A. Proteolysis: from the lysosome to ubiquitin and the proteasome. Nat Rev Mol Cell Biol. 2005;6(1):79-87.

3. Ciechanover A, Brundin P. The ubiquitin proteasome system in neurodegenerative diseases: sometimes the chicken, sometimes the egg. Neuron. 2003;40(2):427-46.

4. Dennissen FJA, Kholod N, van Leeuwen FW. The ubiquitin proteasome system in neurodegenerative diseases: culprit, accomplice or victim? Prog Neurobiol. 2012;96(2):190-207.

5. van Leeuwen FW. Frameshift mutants of amyloid precursor protein and ubiquitin-B in Alzheimer's and down patients. Science American Association for the Advancement of Science. 1998;279(5348):242-7.

6. Gentier RJ, Van Leeuwen FW. Misframed ubiquitin and impaired protein quality control: an early event in Alzheimer's disease. Frontiers in Molecular Neuroscience. Frontiers; $2015 ; 8: 4277$.

7. Vermulst M, Denney AS, Lang MJ, Hung C-W, Moore S, Mosely AM, et al. Transcription errors induce proteotoxic stress and shorten cellular lifespan. Nat Commun. Nature Publishing Group 2015;6: 8065 .

8. Lindsten K, de Vrij FMS, Verhoef LGGC, Fischer DF, Van Leeuwen FW, Hol EM, et al. Mutant ubiquitin found in neurodegenerative disorders is a ubiquitin fusion degradation substrate that 
blocks proteasomal degradation. J Cell Biol. Rockefeller Univ Press 2002;157(3):417-27.

9. van Tijn P, de Vrij FMS, Schuurman KG, Dantuma NP, Fischer DF, van Leeuwen FW, et al. Dose-dependent inhibition of proteasome activity by a mutant ubiquitin associated with neurodegenerative disease. J Cell Sci. The Company of Biologists Ltd. 2007;120(9): 1615-23.

10. Verhoef LGGC, Heinen C, Selivanova A, Halff EF, Salomons FA, Dantuma NP. Minimal length requirement for proteasomal degradation of ubiquitin-dependent substrates. FASEB J. Federation of American Societies for Experimental Biology 2009;23(1):123-33.

11. Krutauz D, Reis N, Nakasone MA, Siman P, Zhang D, Kirkpatrick DS, et al. Extended ubiquitin species are protein-based DUB inhibitors. Nat Chem Biol. 2014;10(8):664-70.

12. Tan Z, Sun X, Hou F-S, H-W O, Hilgenberg LGW, Hol EM, et al. Mutant ubiquitin found in Alzheimer's disease causes neuritic beading of mitochondria in association with neuronal degeneration. Cell Death Differ. Nature Publishing Group 2007;14(10):1721-32.

13. Braun RJ, Sommer C, Leibiger C, Gentier RJG, Dumit VI, Paduch $\mathrm{K}$, et al. Accumulation of basic amino acids at mitochondria dictates the cytotoxicity of aberrant ubiquitin. Cell Rep. Elsevier 2015;10(9):1557-71.

14. Fischer DF, van Dijk R, van Tijn P, Hobo B, Verhage MC, van der Schors RC, et al. Long-term proteasome dysfunction in the mouse brain by expression of aberrant ubiquitin. Neurobiol Aging. Elsevier 2009;30(6):847-63.

15. van Tijn P, Dennissen FJA, Gentier RJG, Hobo B, Hermes D, Steinbusch HWM, et al. Mutant ubiquitin decreases amyloid $\beta$ plaque formation in a transgenic mouse model of Alzheimer's disease. Neurochem Int. 2012;61(5):739-48.

16. Schipanski A, Oberhauser F, Neumann M, Lange S, Szalay B, Krasemann S, et al. The lectin OS-9 delivers mutant neuroserpin to endoplasmic reticulum associated degradation in familial encephalopathy with neuroserpin inclusion bodies. Neurobiol Aging. Elsevier 2014;35(10):2394-403.

17. Irmler M, Gentier RJG, Dennissen FJA, Schulz H, Bolle I, Hölter $\mathrm{SM}$, et al. Long-term proteasomal inhibition in transgenic mice by $\mathrm{UBB}+1$ expression results in dysfunction of central respiration control reminiscent of brainstem neuropathology in Alzheimer patients. Acta Neuropathol. Springer-Verlag 2012;124(2):187-97.

18. Gentier RJG, Verheijen BM, Zamboni M, Stroeken MMA, Hermes DJHP, Küsters B, et al. Localization of mutant ubiquitin in the brain of a transgenic mouse line with proteasomal inhibition and its validation at specific sites in Alzheimer's disease. Front Neuroanat. Frontiers 2015;9:459.

19. Armstrong CL, Krueger-Naug AM, Currie RW, Hawkes R. Constitutive expression of the $25-\mathrm{kDa}$ heat shock protein Hsp25 reveals novel parasagittal bands of Purkinje cells in the adult mouse cerebellar cortex. J Comp Neurol. John Wiley \& Sons, Inc. 2000;416(3):383-97.

20. Apps R, Hawkes R. Cerebellar cortical organization: a one-map hypothesis. Nat Rev Neurosci. 2009;10(9):670-81.

21. Cerminara NL, Lang EJ, Sillitoe RV, Apps R. Redefining the cerebellar cortex as an assembly of non-uniform Purkinje cell microcircuits. Nat Rev Neurosci. Nature Publishing Group 2015;16(2):7993.

22. Armstrong CL, Krueger-Naug AM, Currie RW, Hawkes R. Constitutive expression of heat shock protein HSP25 in the central nervous system of the developing and adult mouse. J Comp Neurol. John Wiley \& Sons, Inc. 2001;434(3):262-74.

23. Armstrong CL, Krueger-Naug AMR, Currie RW, Hawkes R. Expression of heat-shock protein Hsp25 in mouse Purkinje cells during development reveals novel features of cerebellar compartmentation. J Comp Neurol. John Wiley \& Sons, Inc. 2001;429(1):7-21.

24. Goldbaum O, Riedel M, Stahnke T, Richter-Landsberg C. The small heat shock protein HSP25 protects astrocytes against stress induced by proteasomal inhibition. Glia. Wiley Subscription Services, Inc., A Wiley Company 2009;57(14):1566-77.

25. Krueger-Naug AMR, Plumier J-CL, Hopkins DA, Currie RW. Hsp27 in the Nervous System: Expression in Pathophysiology and in the Aging Brain. In: Small Stress Proteins. Berlin, Heidelberg: Springer Berlin Heidelberg; 2002. pp. 235-51. (Progress in Molecular and Subcellular Biology; vol. 28).

26. Sarna JR, Hawkes R. Patterned Purkinje cell death in the cerebellum. Prog Neurobiol. 2003;70(6):473-507.

27. Sillitoe RV, Stephen D, Lao Z, Joyner AL. Engrailed homeobox genes determine the organization of Purkinje cell sagittal stripe gene expression in the adult cerebellum. J Neurosci. Society for Neuroscience 2008;28(47):12150-62.

28. Leto K, Arancillo M, Becker EBE, Buffo A, Chiang C, Ding B, et al. Consensus Paper: Cerebellar Development. The Cerebellum. Springer US; $2015: 1-40$.

29. van Tijn P, Hobo B, Verhage MC, Oitzl MS, Van Leeuwen FW, Fischer DF. Alzheimer-associated mutant ubiquitin impairs spatial reference memory. Physiol Behav. 2011;102(2):193-200.

30. van Tijn P, Verhage MC, Hobo B, Van Leeuwen FW, Fischer DF. Low levels of mutant ubiquitin are degraded by the proteasome in vivo. J Neurosci Res. Wiley Subscription Services, Inc., A Wiley Company 2010;88(11):2325-37.

31. Reeber SL, Arancillo M, Sillitoe RV. Bergmann Glia are Patterned into Topographic Molecular Zones in the Developing and Adult Mouse Cerebellum. The Cerebellum. Springer US; $2014: 1-12$.

32. Armstrong CL, Chung SH, Armstrong JN, Hochgeschwender U, Jeong YG, Hawkes R. A novel somatostatin-immunoreactive mossy fiber pathway asssociated with HSP25-immunoreactive Purkinje cell stripes in the mouse cerebellum. J Comp Neurol. Wiley Subscription Services, Inc., A Wiley Company 2009;517(4):524-38.

33. Chung C, Elrick MJ, Dell'Orco JM, Qin ZS, Kalyana-Sundaram S, Chinnaiyan AM, et al. Heat shock protein beta-1 modifies anterior to posterior Purkinje cell vulnerability in a mouse model of Niemann-pick type C disease. PLoS Genet. Public Library of Science 2016;12(5):e1006042.

34. Braak H, Braak E, Bohl J, Lang W. Alzheimer's disease: amyloid plaques in the cerebellum. J Neurol Sci. 1989;93(2-3):277-87.

35. Joachim CL, Morris JH, Selkoe DJ. Diffuse senile plaques occur commonly in the cerebellum in Alzheimer's disease. Am J Pathol. 1989;135(2):309-19.

36. Lemere CA, Lopera F, Kosik KS, Lendon CL, Ossa J. The E280A presenilin 1 Alzheimer mutation produces increased A342 deposition and severe cerebellar pathology. Nat Med. 1996;2(10):114650 .

37. Sepulveda-Falla D, Matschke J, Bernreuther C, Hagel C, Puig B, Villegas A, et al. Deposition of Hyperphosphorylated tau in cerebellum of PS1 E280A Alzheimer's disease. Brain Pathol. Blackwell Publishing Ltd 2011;21(4):452-63.

38. Wang H-Y, D'Andrea MR, Nagele RG. Cerebellar diffuse amyloid plaques are derived from dendritic $A \beta 42$ accumulations in Purkinje cells. Neurobiol Aging. 2002;23(2):213-23.

39. Sepulveda-Falla D, Barrera-Ocampo A, Hagel C, Korwitz A, Vinueza-Veloz MF, Zhou K, et al. Familial Alzheimer's diseaseassociated presenilin-1 alters cerebellar activity and calcium homeostasis. J Clin Invest. American Society for Clinical Investigation 2014;124(4):1552-67. 